TURIZAM

Volume 13

Issue 1, 58-64 (2009)

\title{
Search Engine Visibility and Language Availability of Travel and Tourism Websites in Serbia
}

\author{
Uglješa Stankov* \\ Vanja Dragićević* \\ Tamara LJ. Pavlović*
}

Received: June 2009 | Accepted: September 2009

\begin{abstract}
The visibility of websites on search engines on the one hand is the basic demand of Internet users, and on the other hand reflects the way website owners create and maintain them. In a large number of tourist sites, the importance of visibility of the domestic tourist sites on the leading search engines is emphasized. The authors have found that travel and tourism websites in Serbia are most visible on the local search engines. For foreign users, in addition to the good visibility, the availability of website content in foreign languages is also important. Only half of the tourist websites in Serbia is available in a foreign language. The research aims to point out to the poor visibility and small availability of content in foreign languages of domestic tourist sites and the need for their improvement.
\end{abstract}

Key words: website, visibility, search engines, foreign languages, tourism, Serbia

\section{Introduction}

The number of websites is constantly growing. In 1995 there were 2 million of registered domain, and in 2004 there were 233 million of them (Kasi, Jain, 2006). Among large number of websites it is crucial for every website to be visible. As much as a good location is important in the trade of products and services in a traditional way, it is also important on the Web. Location value of website matches the number of website visitors.

There are two basic ways of accessing a website. The first is when the Web user already knows which website he/she will visit (knows URL). Another way indicates the situation when a user comes to a website using search engines. The greatest number of Internet users, even $90 \%$, use search engines to find Internet resources (Viney, 2008).

* Faculty of Science, Department of Geography, Tourism and Hotel Management, Trg Dositeja Obradovića 3, Novi Sad, Srbija; ugljesa.stankov@dgt.uns.ac.rs; vanja.dragicevic@dgt.uns.ac.rs, tamara.pavlovic@dgt.uns.ac.rs 
Good visibility on search engines is the goal of search engine marketing. All activities designed to improve Web search results, whether they are paid or not, can be considered as part of search engine marketing.

Internet search engines could be characterized as applications that collect information about Web pages. Collected information mainly consists of keywords or phrases that are possible indicators of the content of Web pages, the page URL, the code of web pages and links that lead to and from them. This information is indexed and stored in the search engine database. Search engine has its own webpage (such as http://www.google.com), which is used for searching. When the search is initiated the algorithm of search engine examines information previously stored in the database. When searching is done, matching terms are presented in form of links that lead to Web pages that match the entered search keywords.

For collecting set of information about Web pages for database search engines, the program called a "robot", "spider" or "crawler" is used. This program literally reviews every site on the Web and gathers keywords and phrases for each webpage, and then stores them in the database.

All elements of the search engine are equally important, but the search algorithms are the base of each search engine, because they determine the way in which data is presented to users. Search algorithms accept the word or phrase to search, examine the database and then display a search result, in form of URL that contains requested website (with or without part of the website). Search algorithms differ from search engine to search engine, so that search results are not the same.

A search result (Web page with keywords that started search) is a consequence of every search activity.

Apart of a search results, website rank (position in the overall list of search results) is also important. If rank is closer to the top of the list of search results, than the website is more significant for the searcher. Since the results are presented in multiple Web pages, more than $84 \%$ of search engine users never view another Web page (Viney, 2008), which particularly emphasizes the importance of a search result ranking.

In the broader sense, search engines can be divided into three categories: primary, secondary, and target search engines. The primary search engines are those that include almost all sites on the Web and they are mainly used (Google, Yahoo, MSN).

Secondary search engines are focused to smaller groups of users, but the scope of the search is general. These search engines do not have so much traffic as the primary, but they are mostly used for regional searches. Users often choose them because of habits. Examples of secondary search engines are Lycos and Ask, and example of domestic secondary engines are Pogodak and Krstarica.

The third group consists of target or topic search engines. These search engines are focused on specific search scopes (medicine, travel, sports, etc.). Examples of these search engines are CitySearch, Yahoo Travel and many others (Ledford, 2008). Search results can be unpaid or paid.

Unpaid (organic, natural) search results are "the best" Web pages that match specific query (keywords, terms, phrases). Most users trust unpaid results and the largest number of visitors (60\%) come to the website using them (Moran, 2000).

Paid search results are related to the activities that use search engines to make profit by including or better ranking certain search results.

Websites, as the most common form of Internet presence, are not often "visible" on search engines. This means that the largest number of Internet users will not be able to find those 
websites. Therefore, a need of creating websites that will satisfy most of search engine requirements appears. This practical need led to a creation of one of the key Internet promotional techniques, which is called search engine optimization - SEO. SEO represents the application of techniques and tactics that enable better positioning of adequate websites in the search results for selected key words that best describe search terms (http://www.draganvaragic.com).

As already noted, in addition to the appearance of data on website in search results, second goal of SEO is to achieve a better rank of search results. Rank depends on: the position of the keyword in the webpage and its frequency, number of links and click-through rate, website traffic etc. The importance of these elements differs between search engines.

The Internet is a field that is in constant process of change. At the same time, search engines are constantly changing their search algorithms, so that the positive results for the search term can quickly turn into a negative one. Therefore, optimization of websites must be a continuous process and be a part of a general plan of Internet promotion.

\section{Methodology}

The data used for research included 260 websites of domestic tourism companies and organizations. The research was conducted in September and October 2008. Considering the importance of certain segments of the tourism industry, websites were divided into several groups: (1) group of travel agencies, (2) group of accommodation sector, (3) group of tourism organizations, (4) group of transport companies and (5) group of travel web portals.

Visibility of websites is determined by searching keywords that represent the names of travel agencies, accommodation facilities, the names of cities, municipalities, transport companies and tourism portal. According to Schegg (2005), the most popular search terms include a combination of hotel name and the city or region where the hotel is located. In this research, location was also included in the search, in case of frequent and generally well-known company names. The existence of desired URL on the first page of search results (10 results) is considered as an existence of visibility of website.

The placement of URLs among the top ten results was indicated as the position of website for the search engine. Average position for groups of websites is obtained by dividing the sum of the positions of websites with the number of all websites in the group.

For determination of visibility in this research authors used Google and Yahoo, as most popular search engines in the world. Pogodak and Krstarica search engines were used as an example of domestic search engines.

The frequency of foreign languages at the domestic tourism websites, as well as the percentage of fully accessible content in a foreign language was determined using structural observation. The percentage of visitors by the country of origin was obtained using Alexa Web service information.

\section{Visibility of domestic tourism websites}

Research results show that tourism websites had the best visibility on domestic search engine Pogodak. Almost three quarters (74.6\%) of links appear in the first 10 search results of this search engine. The second place goes to Google with 70.8\%. On the third place is Krstarica with $61.9 \%$ and on the fourth comes Yahoo with $46.9 \%$ (see Chart 1). 


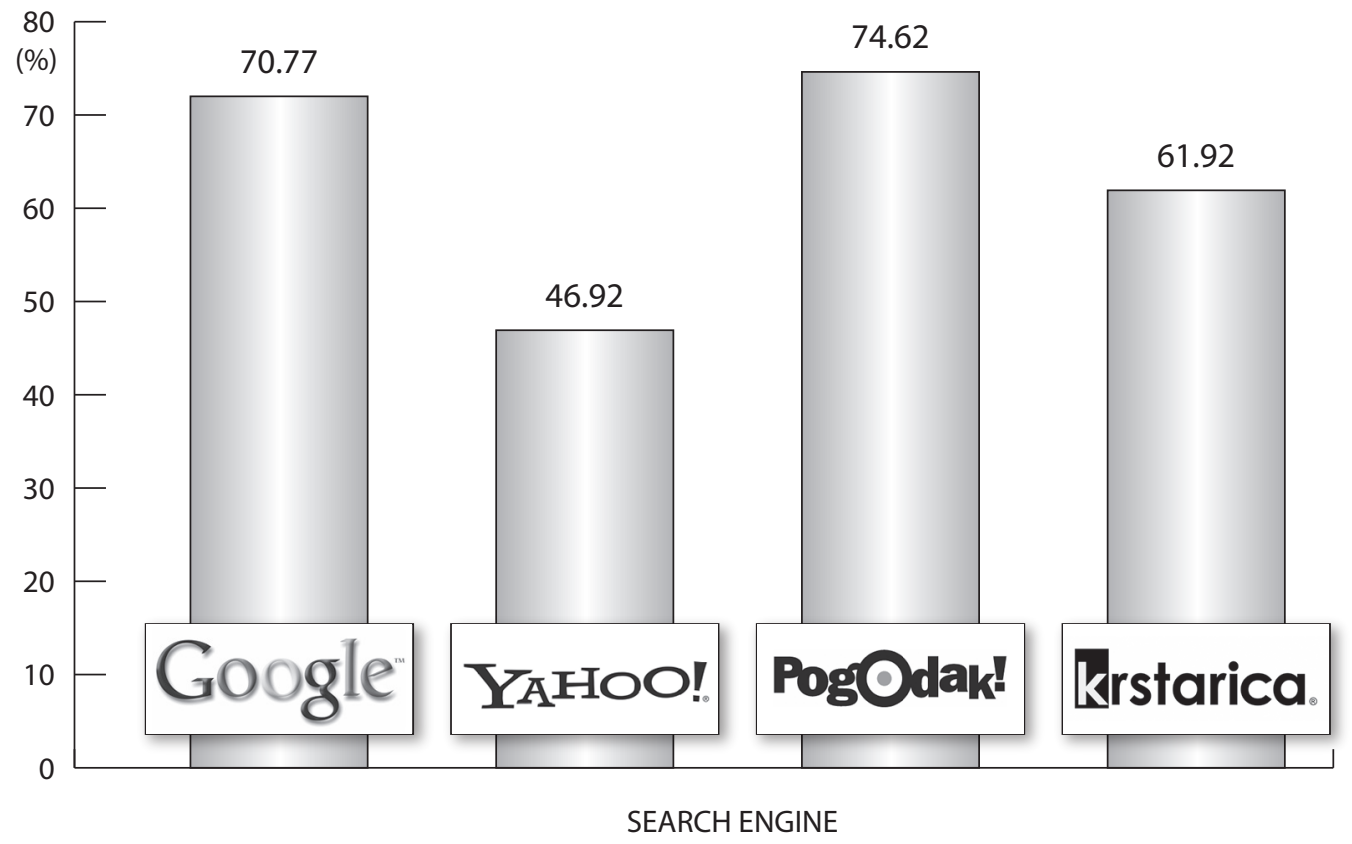

Figure 1. Visibility of domestic tourism websites on Google, Yahoo, Pogodak and Krstarica search engines.

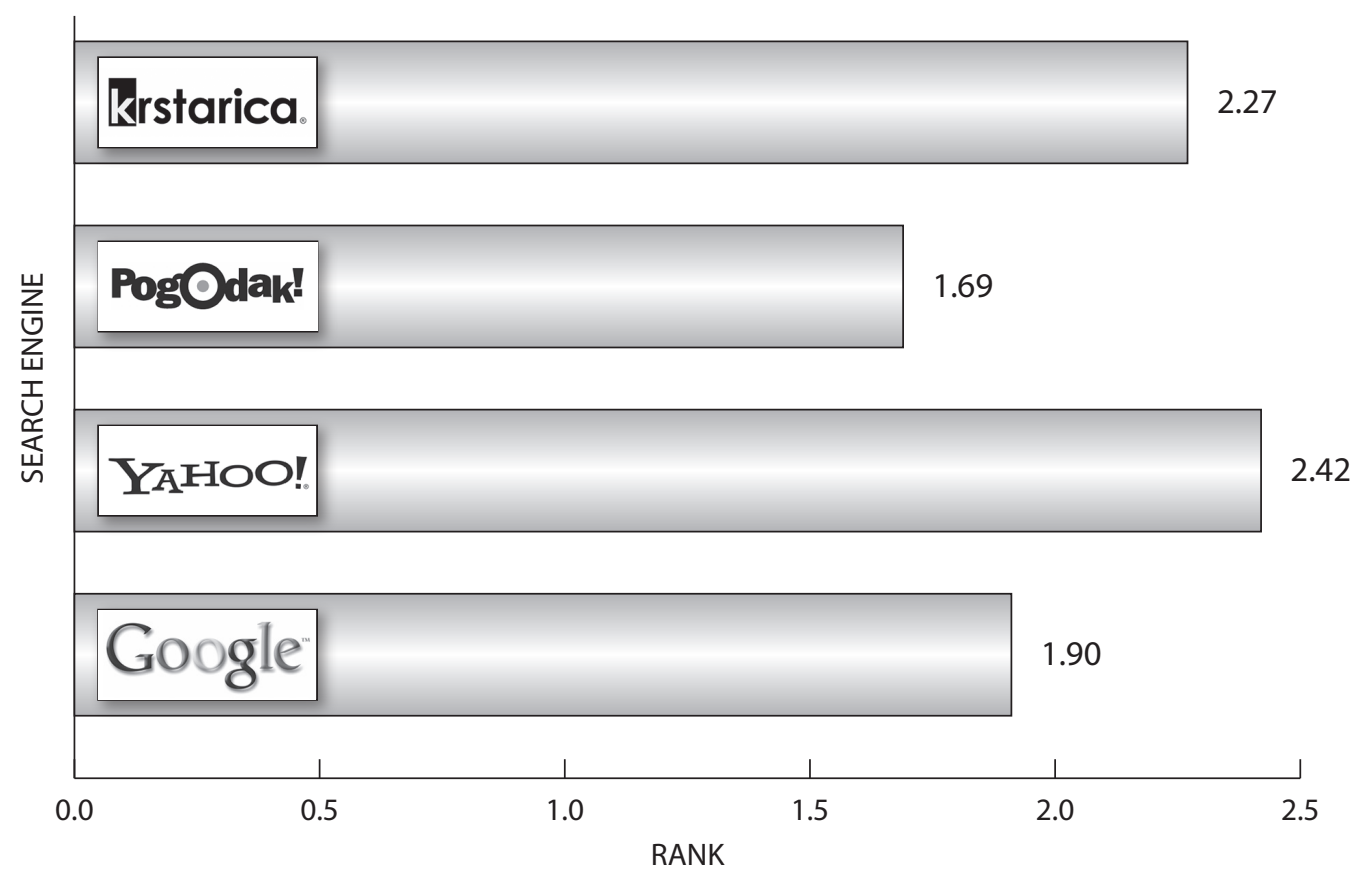

Figure 2. Average position of ranks of tourism websites 
According to presented results, small visibility on domestic and leading search engines can clearly be noted. Even the result of $75 \%$ of visibility is not satisfactory, knowing the importance of visibility on search engines. In this context, a bad situation in the search results is particularly emphasized in Yahoo search engine.

The same sequence of search engines can be seen analysing an average rank position. Tourism websites have the best average position of rank results on Pogodak, 1,69 (best position is marked as 1$)$. On the second place is Google $(1,9)$. Third place goes to Krstarica $(2,27)$ and at the end is Yahoo with 2,42 (see Chart 2).

It should be emphasized that generic results do not represent a constant. They are very variable and depend on numerous parameters. Presented results should be a starting point for the implementation of search engine marketing in the case of already existing websites. Having in mind that the optimization is performed for each website (or even a Web page) separately, presented results should be seen as basic indicators for domestic tourism organizations and companies.

\section{Language availability of websites}

The study found that $73.1 \%$ of visitors on domestic travel and tourism websites come from territory of Serbia and Montenegro ${ }^{1}$. Other visitors come mainly from the territory of former Yugoslavia (Croatia, Bosnia and Herzegovina and Slovenia) and other European countries (Hungary, Netherlands, Switzerland, Germany, Poland, Czech Republic and others).

The aim of the national tourism policy of most countries is to attract foreign tourist demand. Therefore, most information about domestic travel and tourism offer must be presented in understandable language of target markets. In this context, the authors researched how many websites offer content in a foreign language, whether it is complete or partial availability of content in a foreign language and what the structure of these languages is.

It was determined that $47 \%$ of travel and tourist websites offer content in a foreign language. The largest percentage of content in a foreign language provide transport companies (80\%) They are followed by accommodation sector (70\%), tourist organizations (6o\%), and travel portals $(40 \%)$. Only $28 \%$ of travel agencies offer website content in foreign languages. Travel agencies have no interest to offer their content in a foreign language, because domestic market is their main target area.

Besides, the fact that travel websites offer their content in a foreign language, it is important to emphasize that these facilities are not fully available. Looking at the total number of observed websites, $30 \%$ of these websites is fully accessible to foreign language.

If we look at the percentage of full availability of content in a foreign language we note that the accommodation sector has mostly website content that is fully available in a foreign language. This can be a consequence of basic orientation of promotional efforts to foreign demand, but also the consequence of relatively simple website content in this group, which easily can be translated in foreign languages.

The research also determined the structure of foreign languages used on observed tourism websites in Serbia. Chart 4 shows dominance of the English language with 71\%. English is followed by German with $13 \%$, French with $6 \%$ and Hungarian with $4 \%$. Italian and Russian languages are present in $2 \%$ of observed websites and Bulgarian, Macedonian, Romanian and Japanese with $0,5 \%$.

1 During the research Alexa Web service conducted joint statistics for Serbia and Montenegro. 


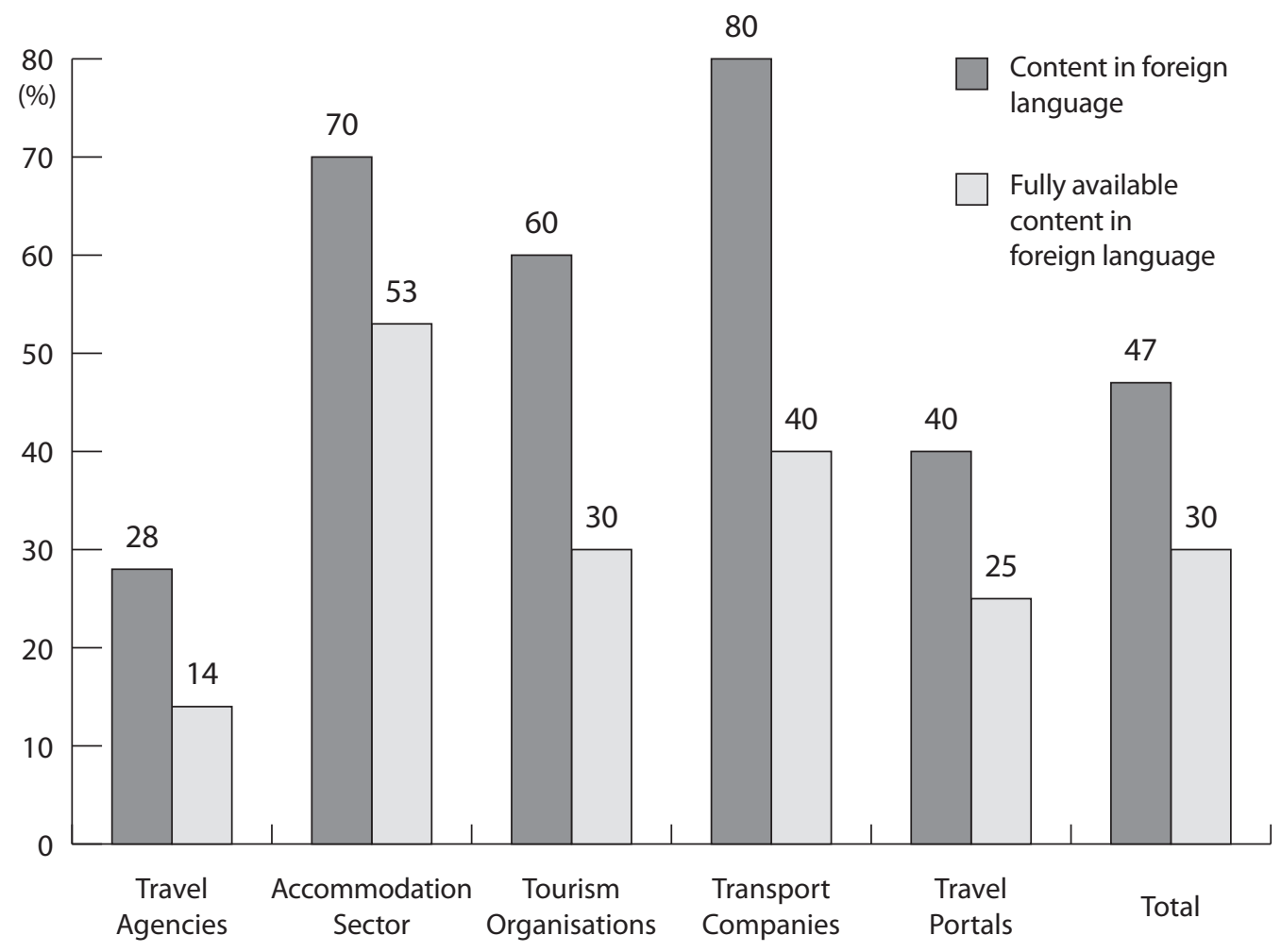

Figure 3. The percentage of travel websites with content in a foreign language and the percentage of full availability of content in a foreign language
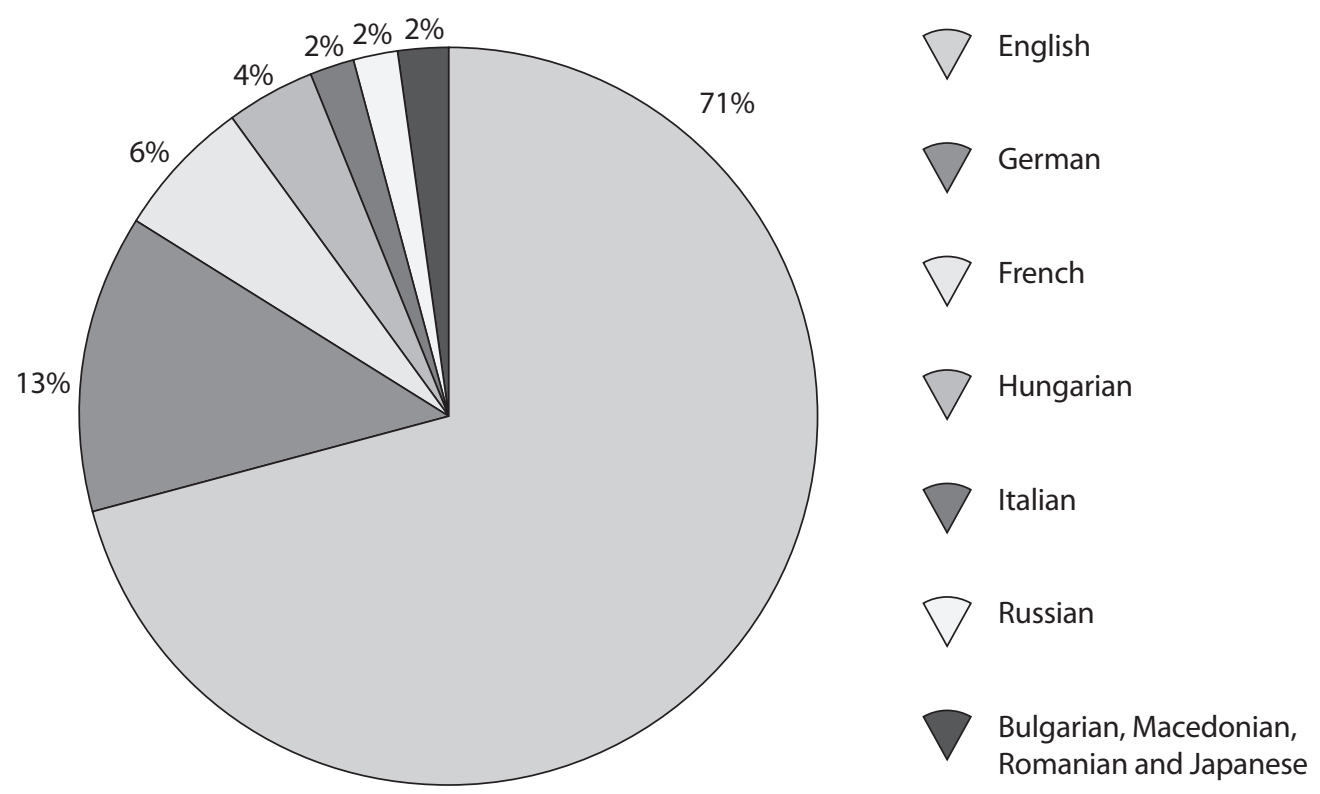

Figure 4. Structure of foreign languages on domestic travel and tourism websites in Serbia 
Except for the English language, there are very small presence of other foreign languages on domestic travel and tourism websites in Serbia. It can be concluded that the choice of languages that appear is relatively good, because they match target markets that are defined in the Strategy of Tourism of the Republic of Serbia (2005). However, there is a lack of Spanish, Polish, Greek, Czech, Slovak and Scandinavian languages.

\section{Conclusion}

Domestic travel websites have relatively small visibility on popular domestic and most popular search engines in the world, with a relatively good rank of search results. Firstly, promotional efforts must be directed to improving visibility in search engines, as one of the key categories of Internet marketing.

English is dominant among the foreign languages on domestic travel and tourism websites. Although appearing, foreign languages (except English) are not represented in sufficient number, so the promotional effects of domestic travel and tourism websites are limited only to English speaking Internet users.

Previously mentioned characteristics of domestic tourist websites limit and make pointless tourist promotion over the Internet. Therefore, it is necessary to take a series of emergency measures. Responsibility for enforcement of these measures should be on Tourist Organization of Serbia and local tourist organizations, travel associations, and especially travel portals that significantly affect the global picture of Serbia as a tourist destination.

\section{References}

Kasi, V., Jain, R. (2006). Internet Search Engines, in Encyclopaedia of E-Commerce, E-Government, and Mobile Commerce, Vol. 1, Idea Group Reference, Hershey.

Ledford, J. (2008). Search Engine Optimization Bible, Wiley Publishing.Indianapolis.

Morgan N., Pritchard A. (200o). Advertising in Tourism and Leisure, Butterworth-Heinemann, Oxford.

Schegga, R., Steinerb, T., Gherissi-Labbena, T., Murphyd, J. (2005). Using Log File Analysis and Website Assessment to Improve Hospitality Websites, in Information and Communication Technologies in Tourism 2005, Springer-Verlag, Wien.

Tourism Strategy of the Republic of Serbia, 2005, Ministry of Trade, Tourism and Services of the Republic of Serbia, Belgrade.

Viney, D. (2008). Get to the Top on Google, Nicholas Brealey Publishing, London.

http://www.alexa.com

http://www.draganvaragic.com 